\begin{tabular}{|c|c|c|c|c|c|c|}
\hline Helium & & & Sonnenrand & & Umgebung & $\begin{array}{c}\text { Sonnenrand Nord- } \mathfrak{u} \text {. Südpol } \\
\text { Mitte beider Linien }\end{array}$ \\
\hline Jewell u. Mahler & Runge u. Paschen ${ }^{1}$ ) & West & Ost & Mittel & der Flecke & Hale \\
\hline $\begin{array}{l}5875.8 \times 2 \\
5876.147\end{array}$ & $\begin{array}{l}5875.870 \\
5876.209\end{array}$ & $\begin{array}{l}5875.857 \\
5876.188\end{array}$ & $\begin{array}{l}5875.824 \\
5876 . \times 75\end{array}$ & $\begin{array}{l}5875.841 \\
5876.182\end{array}$ & $5875.8 \times 5$ & 5875.924 \\
\hline
\end{tabular}

Die Uebereinstimmung der Wellenlänge der Linie $D_{\mathbf{3}} \mid$ und der Protuberanzen, wenn man zunächst von der weniger mit derjenigen der entsprechenden Linie des Heliums ist also grade in dem Falle eine vollkommene, in welchem nach der Dispersionstheorie merkliche Unterschiede auftreten müssten.

Nach diesen Darlegungen liegt keine Veranlassung vor, die älteren Anschauungen über die Natur der Chromosphäre

Potsdam, Kgl. Astrophys. Observatorium, Juni Igor. bekannten Erscheinung des „flash « absieht, zu Gunsten der neuen Theorie zu verlassen, wenn auch zuzugeben ist, dass die interessanten von Herren Julius und Ebert betrachteten Erscheinungen besonders in Gegenwart glühender Natriumdämpfe merkbar werden können.

1) Sitz. d. K. Akad. d. Wiss., Berlin, Juli 1895.

7. Wilsing.

\title{
Beobachtungen der Nova (3.1901) Persei
}

an der Sternwarte des k. und k. Hydrographischen Amtes zu Pola.

Die Helligkeiten der Vergleichsterne wurden der Harvard Photometry entnommen und betragen:



In der Rubrik Beobachter steht

B für den Unterzeichneten

M für den k. u. k. Linienschiffsfähnrich Egon Marchetti

$\mathrm{H}$ 》 》, Rudolf Hohl

$\mathrm{Mk} \gg \gg \quad$ » $\gg$ Richard Miclaučič

$\begin{array}{rcc}\text { I90I } & \text { Beobachter } & \text { Grösse } \\ \text { April I 7 } & \text { H } & 4.6 \\ \text { I 8 } & \text { B, M, H } & 4.2 \\ \text { I 9 } & \text { B, M, H } & 5.6,5.6,5.3 \\ \text { 2 I } & \text { H } & 5.9 \\ 22 & \text { H } & 5.8 \\ 23 & \text { H } & 4.6 \\ \text { 24 } & \text { H } & 5.6 \\ 26 & \text { H } & 5.7 \\ 28 & \text { H } & 5.4\end{array}$

Durchweg wurde um $8^{\mathrm{h}} 30^{\mathrm{m}}$ M.E. Z. beobachtet. Die Beobachtungen März 23-April 2, April 8-1 I geschahen mit freiem Auge, April 3-7 mit einem Handfernrohr, vom 16. April ab mit Binocle.

Pola, Igo I Mai 7 .

Der Vorstand: Ivo Freiherr von Benko, k. u. k. Linienschiffskapitain.

\section{Beobachtungen der Nova (3.1901) Persei.}

Die Helligkeitsschwankungen der Nova Persei wurden von mir bereits Anfangs März wahrgenommen. Da dieselben aber nach der von Prof. Seeliger aufgestellten Erklärung iiber die Entstehung neuer Sterne zunächst durchaus nichț Auffallendes boten, schien mir eine besondere Mittheilung über diese Wahrnehmung nicht angezeigt. Nur ganz kurz habe ich ihrer um die angegebene Zeit in einer hier erscheinenden Tageszeitung Erwähnung gethan.

Die nachfolgenden Helligkeiten der Nova sind die Ergebnisse von Schätzungen, die, durchgehends nach der Argelander'schen Methode mit einem Opernglas von etwa zweimaliger (linearer) Vergrösserung, an jedem klaren Abend und zwar stets $1 \frac{1}{2}$ bis 2 Stunden nach Sonnenuntergang ange- stellt wurden. Als Vergleichssterne dienten bis Mitte März $\varepsilon$ und $v$ Persei, von da ab, je nach der Helligkeit der Nova, die Sterne $v, x, 1,30$ und 36 Persei, bei Helligkeiten der Nova unter der 6. Grösse endlich noch die Objecte BD. $+44^{\circ} 734$ und $+42^{\circ} .795$. Die angenommenen Helligkeiten dieser Vergleichsobjecte sind:

\begin{tabular}{|c|c|c|}
\hline$\varepsilon$ Persei & $3 \cdot 5$ & 30 Persei \\
\hline $\boldsymbol{v} \quad \gg$ & 4.0 & 36 \\
\hline 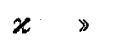 & 4.0 & BD. $+44: 734$ \\
\hline$\gg$ & 5.1 & BD. $+42: 795$ \\
\hline
\end{tabular}

Der Stern 36 Persei hätte nach dem ersten Hagen' schen Verzeichniss, bezw. nach der H. P. die Grösse 5.3; 